\title{
PEMETAAN BAHAYA GEMPA BUMI DAN POTENSI TSUNAMI DI BALI BERDASARKAN NILAI SEISMISITAS
}

\author{
Bayu Baskara $^{1}$, I Ketut Sukarasa ${ }^{1}$, Ardhianto Septiadhi ${ }^{1}$ \\ ${ }^{1}$ Jurusan Fisika, Fakultas Matematika dan Ilmu Pengetahuan Alam, \\ Universitas Udayana, Kampus Bukit Jimbaran, Badung, Bali Indonesia 80361. \\ Email : ketut_sukerasa@unud.ac.id
}

\begin{abstract}
Abstrak
Bali merupakan salah satu daerah rawan bencana gempa bumi dan tsunami karena berada di wilayah pertemuan dua lempeng yaitu lempeng Eurasia dan Indo-Australia yang terletak di sebelah selatan Bali dan zona back arc trust yang terletak di utara Bali. Telah dilakukan penelitian tentang bahaya gempa bumi dan potensi tsunami di Balidiantaranya berdasarkan nilai seismisitas yang diinterpretasikan oleh nilai $\mathrm{b}$ dan a. Penelitian ini menggunakan data gempa bumi pada koordinat $6^{\circ}$ $11^{\circ}$ LS dan $114^{\circ}-116^{\circ}$ BT dimulai pada Januari 1966 sampai Desember 2015 dengan 339 data yang kemudian diolah menggunakan Zmap sehingga diperoleh nilai $b$ sebesar 1,57 $\pm 0,08$ dan nilai a sebesar 10,6 dan magnitudo maksimum sebesar 7,1 Mw. Dari pemetaan nilai b dan a diketahui bahwa daerah yang memiliki nilai $\mathrm{b}$ dan a tertinggi terletak pada daerah lautan untuk wilayah selatan Bali dan daerah Karangasem serta buleleng untuk wilayah utara Bali. Selanjutnya untuk pemetaan tsunami di Bali menggunakan aplikasi TOAST diperoleh daerah rawan tsunami di Bali yaitu Pantai Kuta, Buleleng Timur dan Karangasem.
\end{abstract}

Kata Kunci: Seismisitas, Gempa Bumi, Tsunami, Bali.

\begin{abstract}
Bali is one of the areas prone to earthquake and tsunami as being at the junction of two plates, namely the Eurasian plate and the Indo-Australian plate is located in the south of Bali and back arc trust zones are located in the North of Bali. We need research on the potential dangers of earthquakes and tsunami in Bali are based on the value of seismicity which is interpreted by the value of $b$ and $a$. This study uses earthquake data on the coordinates $6^{\circ}-11^{\circ}$ SLand $114^{\circ}-116^{\circ}$ EL with 339 data that was processed using Zmap in order to obtain the value of $b$ at $1.57 \pm 0.008$ and the value of a is 10.6 and maximum magnitude of $7.1 \mathrm{Mw}$. From mapping the values of $b$ and a known area that has the highest value of $b$ and a lies in the sea area to the south of Bali, Karangasem and Buleleng to the northern region of Bali. Furthermore, for mapping the tsunami in Bali using the TOAST application obtained tsunami prone areas of Bali, Kuta Beach, East Buleleng and Karangasem.
\end{abstract}

Keywords: Seismicity, Earthquake, Tsunami, Bali.

\section{PENDAHULUAN}

Gempa bumi adalah getaran permukaan tanah yang dikaibatkan oleh pelepasan energi terakumulasi secara tibatiba. Gempa bumi dapat disebabkan oleh berbagai hal, diantranya patahan batuan/sesar (Muhammad,2008). Gempa bumi sering melanda daerah-daerah di Indonesia, hal ini dikarenakan Indonesia dilalui oleh tiga lempeng yaitu lempeng Indo-Australia, lempeng Eurasia, dan lempeng Pasifik. Pertemuan lempeng IndoAustralia dan Eurasia membentang sepanjang barat sumatera, selatan Jawa, Bali dan Nusa Tenggara. Sedangkan pertemuan lempeng Eurasia dan lempeng pasifik terletak di sepanjang maluku (Rahmadi,2008). 
Bali merupakan salah satu wilayah Indonesia yang termasuk daerah rawan gempa bumi. Karena Bali diapit oleh dua sumber gempa bumi, yaitu zona subduksi di sebelah selatan Bali yang merupakan pertemuan dua lempeng yaitu lempeng IndoAustralia yang bergerak dari selatan ke utara dan lempeng Eurasia yang bergerak dari utara ke selatan. Adapun sebelah utara Bali terdapat zona Back arc trust yang membentang dari utara Bali sampai ke Flores (Hapsoro,2010). Berdasarkan catatan BMKG, gempa bumi beberapa kali melanda Bali. Diantaranya gempa bumi tahun 1816 yang disebut Gejer Balimenewaskan sedikitnya 1500 orang. Gempa bumi ini juga menimbulkan gelombang tsunami yang menerjang sepanjang pesisir Karangasem dan buleleng. Selanjutnya gempa bumi seririt pada tahun 1976 dan gempa bumi yang dua kali melanda Karangasem yaitu pada tahun 1979 dan 2004 (Darsono,2016). Berdasarkan uraian tersebut maka Bali dapat digolongkan termasuk daerah rawan gempa bumi dan berpotensi terjadi tsunami. Oleh karena itu perlu diadakannya penelitian tentang bahaya gempa bumi dan potensi tsunami di Bali.

\section{TINJAUAN PUSTAKA}

\subsection{Teori Gempa Bumi}

Bila dua buah lempeng bertumbukan, maka pada daerah batas antara dua lempeng akan terjadi tegangan. Salah satu lempeng akan menyusup ke bawah lempeng yang lain, inilah yang disebut subduksi. Pada umumnya lempeng samudera akan menyusup ke bawah lempeng benua, hal ini dikarenakan densitas lempeng samudera lebih besar dibandingkan dengan lempeng benua. Apabila tegangan tersebut telah sedemikian besar sehingga melampaui kekuatan maksimumnya, maka akan terjadi patahan pada kulit bumi pada daerah terlemah. Kulit bumi yang patah tersebut akan melepaskan energi atau tegangan sebagian atau seluruhnya untuk kembali ke keadaan semula. Peristiwa pelepasan energi ini disebut gempabumi (Pepen,2008).

\subsection{Teori Tsunami}

Tsunami adalah perpindahan badan air yang terjadi karena adanya gangguan impulsif pada laut. Gangguan impulsif tersebut terjadi akibat adanya perubahan bentuk dasar laut secara tiba-tiba dalam arah vertikal atau dalam arah horizontal seperti gempa bumi (Trianawati,2008).

Beberapa syarat terjadinya tsunami yang diakibatkan oleh gempa bumi adalah sebagai berikut:

a. Gempa bumi yang berpusat di tengah laut

b. Gempa Bumi dengan kedalaman dibawah $60 \mathrm{~km}$

c. Gempa bumi dengan kekuatan $\geq 6,5$ $\mathrm{Mw}$

d. Gempa bumi dengan pola sesar naik atau turun.

\subsection{Hubungan Frekuensi dengan Magnitudo Gempa Bumi}

Jumlah gempa $\mathrm{N}$ dengan magnitudo M, persamaan Guttenberg-Richer dapat dinyatakan dengan persamaan 2.1 (Rahmadi,2008).

$$
\log N=a-b \cdot M
$$

Dimana :

$$
\begin{aligned}
& \mathrm{N}=\text { jumlah gempa } \\
& \mathrm{a}, \mathrm{b}=\text { konstanta } \\
& \mathrm{M}=\text { magnitudo }
\end{aligned}
$$

Nilai a dan b disebut nilai seismisitas, yaitu nilai yang menunjukkan tingkat kegempaan suatu daerah. Nilai a yaitu menyatakan tingkat keaktifan gempa bumi disuatu daerah yang sedang diamati, sedangkan nilai b menyatakan keadaan tektonik di daerah yang sedang diamati atau tingkat kerapuhan batuan (Rahmadi,2008).

\section{METODE PENELITIAN}

Penelitian ini menggunakan beberapa software dalam pengolahannya yaitu, Microsoft Office 2013, Google Earth, matlab R2008a, Zmap, dan TOAST. Data yang digunakan pada penelitian ini adalah data sekunder dengan parameter gempa bumi yaitu 
waktu kejadian, koordinat kejadian, kedalaman, dan magnitudo gempa bumi. Data tersebut diperoleh dari portal data seismologi United State Geological Survey (USGS) dengan waktu kejadian dimulai tahun 1966-2015, kedalaman gempa lebih kecil dari $300 \mathrm{~km}$ dan magnitudo diatas 3 . Adapun daerah penelitian terletak pada koordinat $6^{\circ}-11^{\circ}$ LS sampai $114^{\circ}-116^{\circ} \mathrm{BT}$.

Tahapan pengolahan data pada penelitian ini adalah sebagai berikut:

1. Menghimpun data gempa bumi sesuia dengan parameter yang telah ditentukan

2. Mengkonversi magnitudo gempa bumi ke dalam magnitudo momen (Mw). Hal ini dilakukan karena Mw tidak mengalami saturasi. Adapun konversi magnitudonya dapat dilakukan dengan persamaan seperti pada Tabel 3.1

Tabel 3.1 Konversi magnitudo

\begin{tabular}{|c|l|}
\hline No. & \multicolumn{1}{|c|}{ Korelasi magnitudo } \\
\hline 1 & $\mathrm{Mw}=0,143(\mathrm{Ms})^{2}-1,051(\mathrm{Ms})+7,285$ \\
\hline 2 & $\mathrm{Mw}=0,114(\mathrm{Mb})^{2}-0,556(\mathrm{Mb})+5,560$ \\
\hline 3 & $\mathrm{Mw}=0,787(\mathrm{Me})-1,537$ \\
\hline 4 & $\mathrm{Mb}=0,125(\mathrm{Ml})^{2}-0,389(\mathrm{Ml})+3,513$ \\
\hline
\end{tabular}

Keterangan :

Mw = Magnitudo Momen

Ms = Magnitudo Surface

$\mathrm{Mb}=$ Magnitudo Body

$\mathrm{Me}=$ Magnitudo Energi

$\mathrm{Ml}=$ Magnitudo Lokal

Md = Magnitudo Durasi

3. Menyeleksi data gempa bumi dengan magnitudo diatas $5 \mathrm{Mw}$.

4. Menghitung dan membuat pemetaan nilai b dan a dengan menggunakan software Zmap 6.0.

5. Menghitung nilai magnitudo maksimum dengan menggunakan persamaan.

6. Membuat pemetaan potensi tsunami menggunakan aplikasi TOAST dengan parameter-parameter tertentu. Parameter yang digunakan adalah magnitudo maksimum, frekuensi kedalaman tertinggi, dan karakteristik fault.

\section{HASIL DAN PEMBAHASAN}

Data kejadian gempa bumi USGS dengan parameter kedalaman $\leq 300 \mathrm{~km}$ dan magnitudo $\geq 5 \mathrm{Mw}$ serta waktu kejadian gempa bumi dimulai pada Januari 1966 sampai Desember 2015 untuk wilayah Bali dengan koordinat $6^{\circ}-11^{\circ} \mathrm{LS}$ dan $114^{\circ}$ $116^{\circ}$ BT diperoleh sebanyak 339 kejadian gempa bumi.

\subsection{Menghitung Nilai Seismisitas dan Magnitudo Maksimum}

Perhitungan dan pemetaan nilai $b$ dan a pada penelitian ini menggunakan software Zmap. Adapun hasil perhitungan nilai $b$ dan a dapat diperlihatkan seperti pada Gambar 4.1 Dari perhitungan diperoleh nilai b sebesar 1,57 $\pm 0,08$ dan nilai a sebesar 10,6.nilai $\mathrm{b}$ menunjukkan tingkat kerapuhan batuan pada suatu wilayah. Dimana semakin besar nilai b maka semakin rapuh batuan diwilayah tersebut. Nilai b yang diperoleh tergolong tinggi, dimana rentang nilai $b$ biasanya antara 0,3 - 1,8 (Hurtig,1984). Hal ini menunjukkan bahwa Bali tergolong daerah yang memiliki batuan yang rapuh sehingga mudah terjadi gempa bumi. Adapun nilai dari a menunjukkan tingkat

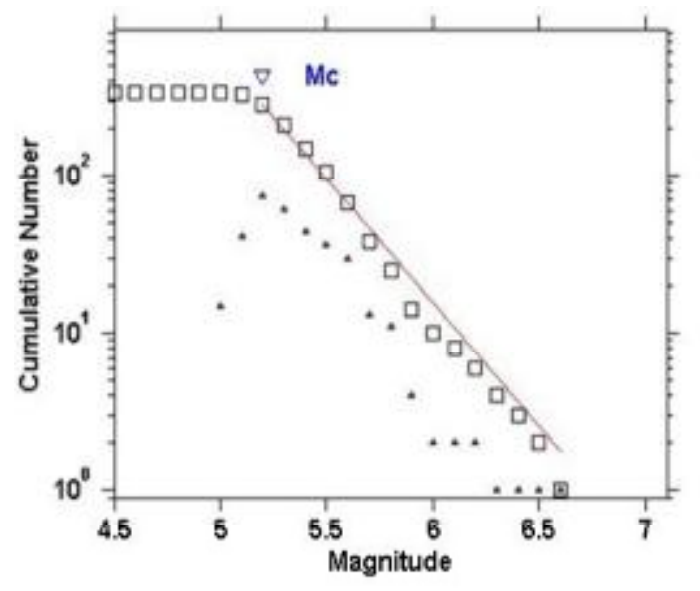

Maximum Likelihood Solution

b-value $=1.57+j-0.08$, a value $=10.6$, a value $($ annual $)=8.93$ Magnitude of Completeness $=5.2$

Ket: $\quad=$ Nilai Kumulatif $; \Delta=$ Nilai Non-Kumulatif; $\nabla=$ Nilai Mc $; *=$ Nilai Kumulatif dan Non-Kumulatif

Gambar 4.1 Kurva distribusi frekuensi gempa bumi di Bali 


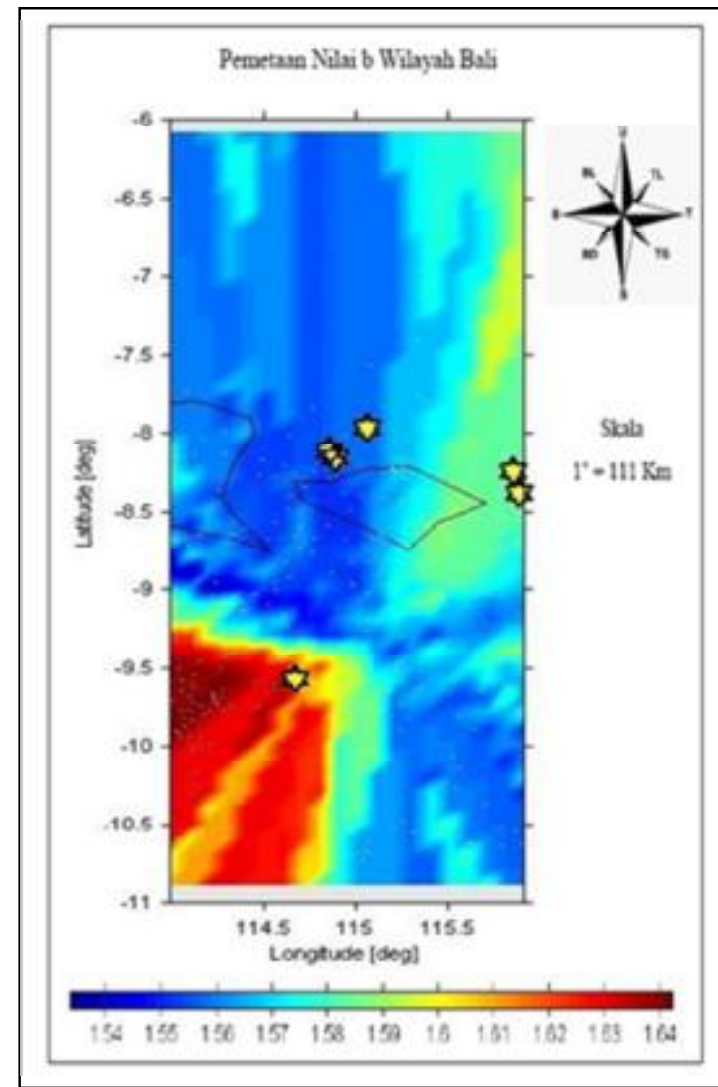

Gambar 4.2Pemetaan nilai a

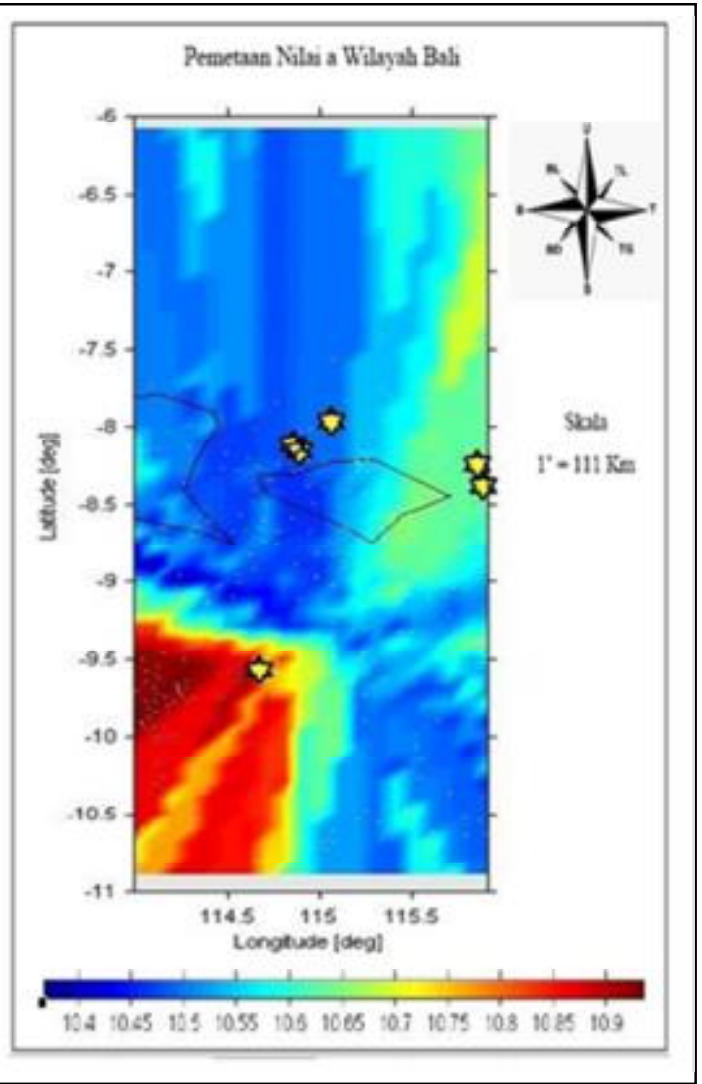

Gambar 4.3 Pemetaan nilai b keseringan gempa bumi. Dimana nilai a yang diperoleh tergolong besar jika dibandingkan daerah lain seperti Gorontalo yakni sebesar 9,4 (Nutrifiani,2014), tetapi masih lebih kecil jika dibandingkan nilai a daerah Jawa Timur yang mencapai 11,7 (Jihan,2013). Adapun dengan nilai $b$ dan a dapat diperoleh magnitudo maksimum yaitu sebesar 7,1 Mw, dimana nilai magnitudo maksimum ini menujukkan magnitudo tertinggi apabila terjadi gempa bumi di Bali

\subsection{Pemetaan Nilai Seismisitas}

Pemetaan nilai seismisitas ditunjukkan dengan pemetaan nilai $\mathrm{b}$ dan $\mathrm{a}$, seperti pada Gambar 4.2 dan Gambar 4.3. Dari Gambar4.2 dan Gambar 4.3 dapat diketahui bahwa wilayah Bali yang memiliki tingkat kerapuhan batuan serta tingkat keseringan gempa bumi dengan nilai tertinggi berada pada daerah sekitar Karangasem Utara dan Buleleng Timur untuk wilayah Bali Utara. adapun untuk wilayah Bali Selatan berada pada wilayah lautan. Hal ini mengindikasikan bahwa daerah Karangasem Utara dan Buleleng Timur rawan terjadi gempa bumi.

\subsection{Pemetaan Potensi Tsunami di Bali}

Pemetaan potensi tsunami dilakukan dengan membagi Bali menjadi dua wilayah, yaitu Bali bagian utara dan Bali bagian selatan dengan mgnitudo dan kedalaman yang sama, dengan menggunakan parameter fault yang berbeda mengikuti karakteristik faultmasing-masing sumber gempa pada kedua wilayah tersebut. Pemetaan ini menggunakan software TOAST.

\subsubsection{Pemetaan potensi tsunami di Bali utara}

Pemetaan ini dilakukan dengan memasukkan beberapa parameter yaitu Magnitudo 7,1, kedalaman $30 \mathrm{~km}$, koordinat $7,8^{\circ} \mathrm{LS}$ dan $115^{\circ} \mathrm{BT}$ dan parameter fault dengan jenistrustfault , strike $133,8^{\circ}$, dip $24^{\circ}$, serta rake $121^{\circ}$. Adapun setelah 
dilakukan running menggunakan TOAST diperoleh hasil seperti pada Gambar 4.4

Pada Gambar 4.4 dapat dilihat daerah-daerah yang terkena dampak apabila terjadi tsunami dengan parameter yang telah ditentukan. Daerah dengan dampak terbesar adalah Karangasem Utara dan Buleleng Timur dengan status siaga. Adapun daerah lain masih berstatus waspada. Data daerah yang terkena dampak, ketinggian gelombang, waktu tempuh serta statusnya dapat dilihat pada Tabel 4.1.

Tabel 4.1 menunjukkan bahwa apabila terjadi tsunami di Balidengan sumber gempa bumi di utara Bali maka daerah yang pertama kali terkena dampak adalah Karangasem Utara dan Buleleng Timur dengan waktu kurang dari 5 menit. Sedangkan daerah lainnya membutuhkan waktu lebih dari 10 menit.

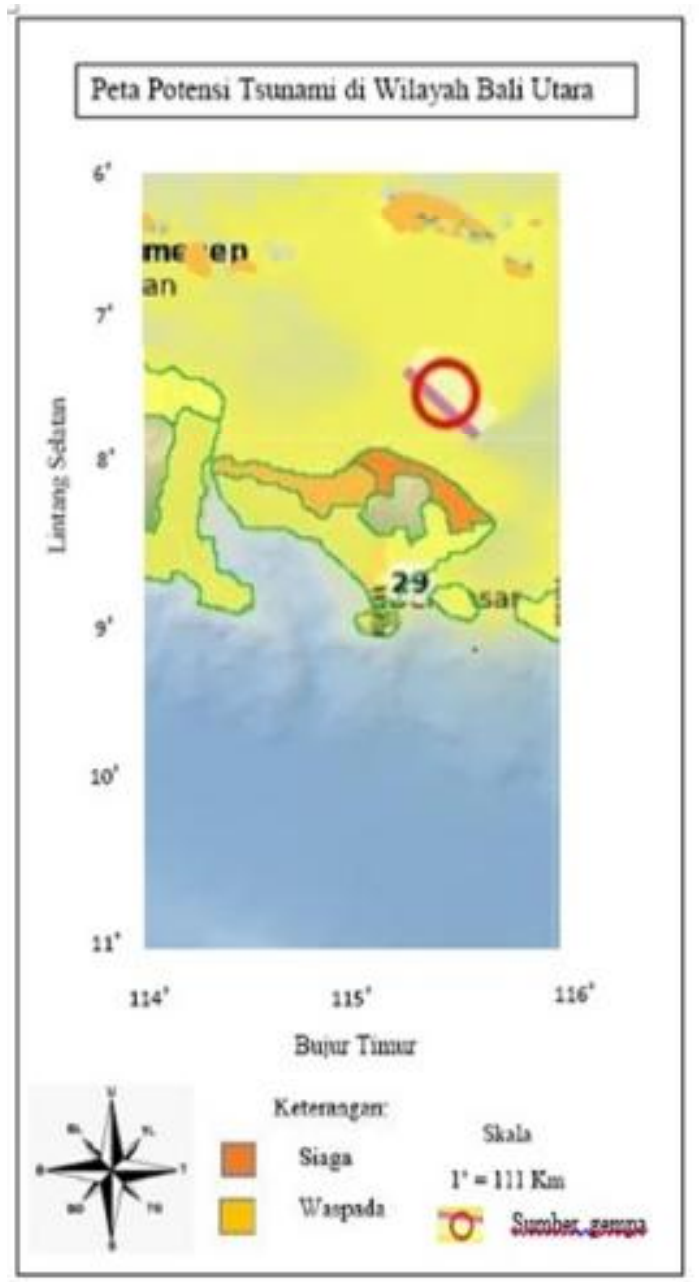

Gambar 4.4 Pemetaan potensi tsunami di Bali
Tabel 4.1 Daftar daerah yang terkena dampak tsunami di Bali utara

\begin{tabular}{|c|l|c|c|c|}
\hline No & Daerah & $\begin{array}{l}\text { Keting } \\
\text { gian } \\
\text { Gelom } \\
\text { bang } \\
(\mathrm{m})\end{array}$ & $\begin{array}{c}\text { Waktu } \\
\text { Tempuh } \\
\text { (Menit) }\end{array}$ & Status \\
\hline & $\begin{array}{l}\text { Buleleng } \\
\text { Bagian } \\
\text { Timur }\end{array}$ & 0,69 & $04: 30$ & Siaga \\
\hline 2 & $\begin{array}{l}\text { Karangasem } \\
\text { Utara }\end{array}$ & 0,61 & $04: 00$ & Siaga \\
\hline 3 & $\begin{array}{l}\text { Buleleng } \\
\text { Barat }\end{array}$ & 0,41 & $10: 00$ & Waspada \\
\hline 4 & Pantai Kuta & 0,33 & $24: 30$ & Waspada \\
\hline 5 & Pantai Sanur & 0,25 & $24: 30$ & Waspada \\
\hline
\end{tabular}

\subsubsection{Pemetaan potensi tsunami di Bali Selatan}

Pemetaan ini dilakukan dengan memasukkan beberapa parameter yaitu magnitudo 7,1, kedalaman $30 \mathrm{~km}$, Koordinat : $79,7^{\circ} \mathrm{LS}$ dan $114,8^{\circ} \mathrm{BT}$ dan parameter fault dengan jenisnormal fault, strike $275,8^{\circ}$, dip $23^{\circ}$, serta rake $125^{\circ}$. Adapun setelah dilakukan running menggunakan TOAST diperoleh hasil seperti pada Gambar 4.5.

Pada Gambar 4.5 dapat dilihat bahwa daerah yang terkena dampak paling besar apabila terjadi tsunami dengan sumber gempa bumi di Bali Selatan adalah sepanjang pantai Bali selatan. Diantaranya adalah pantai Kuta, Nusa Penida, dan lainnya. Data daerah yang terkena dampak, ketinggian gelombang, waktu tempuh serta statusnya dapat dilihat pada Tabel 4.2. Tabel 4.2 menunjukkan bahwa apabila terjadi tsunami di Balidengan sumber gempa bumi di selatan Bali, maka daerah yang pertama kali terkena dampak adalah Pantai Kuta dan Pulau Nusa Penida dengan waktu kurang dari 10 menit. Sedangkan daerah lainnya membutuhkan waktu lebih dari 10 menit. 


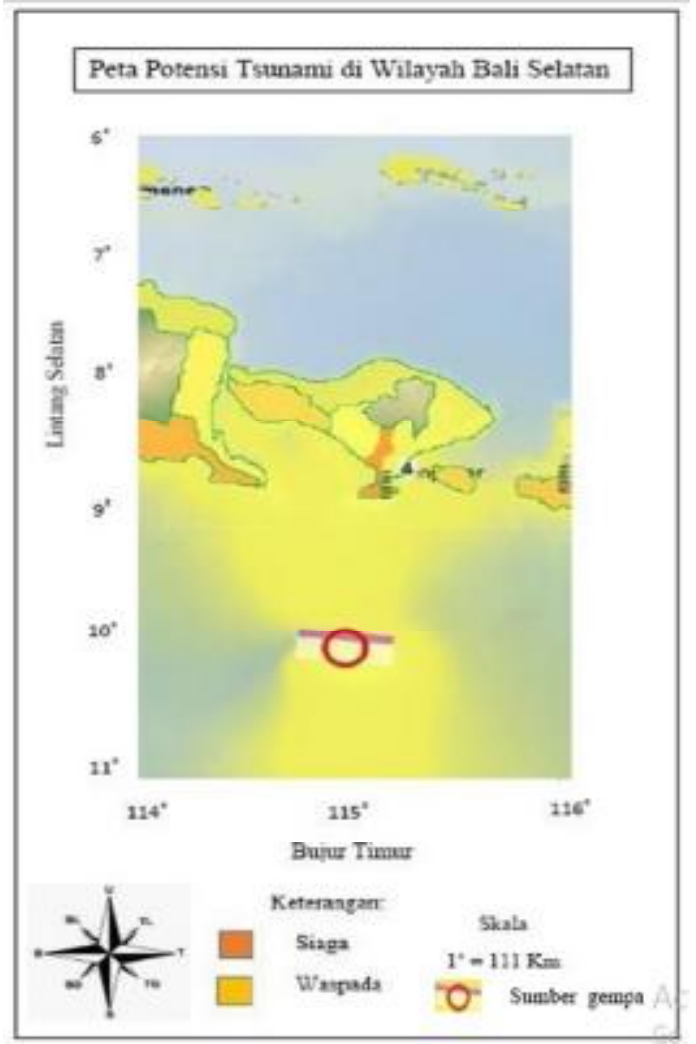

Gambar 4.5 Pemetaan potensi tsunami di Bali selatan

Tabel 4.2 Daftar daerah yang terkena dampak tsunami di Bali selatan

\begin{tabular}{|c|l|l|l|l|}
\hline No & Daerah & $\begin{array}{l}\text { Keting } \\
\text { gian } \\
\text { Gelom } \\
\text { bang } \\
\text { (m) }\end{array}$ & $\begin{array}{c}\text { Waktu } \\
\text { Tempuh } \\
\text { (Menit) }\end{array}$ & Status \\
\hline 1 & Pantai Kuta & 0,47 & $08: 00$ & Siaga \\
\hline 2 & $\begin{array}{l}\text { Pulau Nusa } \\
\text { Penida }\end{array}$ & 0,35 & $09: 00$ & Waspada \\
\hline 3 & Jembrana & 0,34 & $19: 00$ & Waspada \\
\hline 4 & Tabanan & 0,22 & $27: 00$ & Waspada \\
\hline 5 & Klungkung & 0,21 & $17: 00$ & Waspada \\
\hline
\end{tabular}

\section{KESIMPULAN}

Adapun kesimpulan yang diperoleh dari penelitian ini sebagai berikut:

1. Nilai seismisitas yang diinterpretasikan oleh tingkat kerapuhan batuan (nilai b) dan tingkat keseringan gempa bumi (nilai a) yang di peroleh untuk daerah Bali sebesar 1,57 $\pm 0,08$ dan 10,6.

2. Nilai magnitudo maksimum gempa bumi di Bali berdasarkan data penelitian diperkirakan sebesar 7,1 Mw.
3. Bali merupakan daerah rawan gempa bumi dimana daerah paling rawan untuk didaratan adalah Karangasem dan Buleleng, serta Bali memiliki potensi tsunami yang cukup tinggi dengan dampak terbesar adalah Pantai Kuta, Buleleng Timur dan Karangasem Utara dengan status siaga.

\section{DAFTAR PUSTAKA}

Darsono. Sejarah Gempa Bumi di Bali, Badan Meteorologi Klimatologi dan Geofisika, http://balai3.denpasar.bmkg.go.id/sejar ah-gempa-merusak, Diakses pada tanggal 5 Maret 2016.

E. Hurtig and H siller. 1984. "Earthquakes and Seismic Hazard". Academy verlag. Berlin.

Hapsoro. "Analisis Probabilitas Gempa Bumi Daerah Bali dengan Distribusi Poison”. Stasiun Geofisika Sanglah, Denpasar.

Nia Sonaya, Jihan. 2013. "Survey dan Analisis Seismisitas Wilayah Jawa Timur Berdasarkan Data Gempa Bumi Periode 1999-2013 sebagai Upaya Mitigasi Bencana Gempa Bumi”. Jurusan Fisika. FMIPA. Universitas Negeri Surabaya. Surabaya.

Nutrifiani. 2014. "Identifikasi Sesar di Wilayah Gorontalo dengan Analisis Mekanisme Bola Fokus". Jurusan Fisika. FMIPA. UNSRAT. Manado.

Reza,Muhammad. 2008. “ Studi Mekanisme Sumber Gempa Bumi Nias 2005”, Program Pendidikan Diploma III, Jurusan Geofisika, Akademi Meteorologi dan Geofisika,Jakarta.

Supendi,Pepen. 2008. "Analisis Aktifitas Seismik di Jawa Barat dan sekitarnya". Program Pendidikan Diploma III, Jurusan Geofisika, Akademi Meteorologi dan Geofisika,Jakarta.

Tri Wardana,Rahmadi.2008. "Analisa Statistik Tingkat Keaktifan Gempa Bumi di Daerah Jawa Timur dan Sekitarnya", Program Pendidikan Diploma III, Jurusan Geofisika, 
Akademi Meteorologi dan Geofisika,Jakarta.

Trianawati sugito,S.T,M.T. 2011. 2008. "Tsunami". Jurusan Pendidikan Geografi. Universitas Pendidikan Indonesia. Jakarta. 